1 Use of Phase Change Materials to develop Electrospun Coatings of interest in Food

2

3

4

$5 \quad$ Lagaron* $^{*}$

6 Novel Materials and Nanotechnology Group, IATA-CSIC, Avda. Agustin Escardino 7,

746980 Paterna (Valencia), Spain.

8

$9 \quad *$ Corresponding author. Prof.; Tel.: (+34) 963900022 ext: 2512; Fax: (+34) 9636363

10

11

12

13

14

\section{Packaging Applications}

01; E-mail address: lagaron@iata.csic.es
3

4 


\section{ABSTRACT}

In the present study, a heat management PS tray containing an ultrathin fiber-structured PS/PCM coating was prepared by using high throughput electrohydrodynamic processing. To this end, polystyrene (PS) was used as the encapsulating matrix of a commercial phase change material (PCM) called RT5 (a blend of paraffins with a transition temperature at $5^{\circ} \mathrm{C}$ ), by using the electrospinning technique. With the aim of imparting heat management capacity to the trays, the PS tray was coated by the Management materials $\cdot$ Food packaging $\cdot$ Encapsulation PS/PCM ultrathin fiber mats and a soft heat treatment was applied to improve the adhesion between the layers. Results showed that RT5 could be properly encapsulated inside the PS matrix, with a good encapsulation efficiency (ca. 78\%) and the developed PS fibers had a heat storage capacity equivalent to $\sim 34 \mathrm{wt} . \%$ of the neat PCM. The effect of storage time and temperature was evaluated on the heat storage capacity of the developed PS-trays with the ultrathin fiber-structured PS/PCM layer. The heat storage capacity was affected not only by the storage time, but also by the temperature. This work adds a new insight on the development of heat management polymeric materials of interest in food packaging applications, in order to preserve the quality of refrigerated packaged food products. Although the electrohydrodynamic processing seems to be a promising alternative to develop heat management materials, further works will be focused on the improvement of heat storage capacity and efficiency of the developed packaging materials along storage time.

Keywords Phase change material - Electrohydrodynamic processing - Heat 


\section{INTRODUCTION}

Maintaining the cold chain during the commercialization of certain food products is one of the key aspects to ensure food safety and food quality. Refrigeration temperatures are used for preventing or slowing down microbial, physiological and chemical changes in food produced by microbial, chemical and/or enzymatic activity. Along the cold chain there can be temperature variations which will consequently have negative effects on food due to crystal ice growth, acceleration of chemical reactions and/or microorganism growth, which could result in a reduction of quality and may shorten the shelf-life of the food products. Therefore, there is a great interest on finding new strategies to reduce temperature fluctuations along the cold chain. In this sense, the packaging can be designed to play an active role to maintain the food temperature within desired limits and, thus, to ensure the quality, safety and increase the shelf-life of the products (James et al., 2006). However, traditional commercial packages do not provide any protection for maintaining the cold chain. An strategy already proposed to impart thermal buffering capacity to standard packaging materials is based on the development of thermal energy storage structures through the addition of, for example, phase change materials (PCMs) (Chalco-Sandoval et al., 2014, Gin and Farid 2010 Oró et al. 2012) within the polymeric structures (Oró et al. 2013). This strategy has been used by several researchers such as Yannick (2006) who patented a method to manufacture an insulated container used to transport and store ice cream, and Laguerre et al. (2008) who developed and validated a mathematical model to predict the product temperature at certain locations within an insulated container equipped with PCM. However, little information exists in the literature about the incorporation of encapsulated PCM structures into polymeric matrices for food packaging purposes, either in the form of multilayer or in nanocomposites. Chalco-Sandoval et al., 2014 developed PS multilayer- 
based heat storage structures based on PS films coated with PCL/PCM electrospun layers. An additional PCL electrospun layer (without PCM) was also electrospun in some cases to retain PCM during film storage.

Phase change materials (PCMs) are substances that undergo a phase transition at a specific temperature and, as a result, they are able to absorb and release latent heat with a very small variation in temperature (Jin et al. 2010). PCMs could be used during transport, storage and distribution stages to maintain the cold chain of solid food, beverages, pharmaceutical products, textile industry, blood derivatives, electronic circuits, cooked food, biomedical products and many others (Oró et al. 2012). The most commonly used phase change materials are paraffin waxes, fatty acids, eutectics and hydrated salts (Farid et al. 2004). Paraffin compounds fulfill most of the requirements for being used as PCMs, as they are reliable, predictable, non-toxic, chemically inert and stable below $500^{\circ} \mathrm{C}$. They also show little volume changes on melting and have low vapor pressure in the melt form (Sharma et al. 2009). Direct incorporation of PCMs into packaging structures is difficult because of their low thermal stability, low thermal conductivity and some of them are liquid at ambient temperature (Fang et al. 2009). Microencapsulation of the PCMs is a plausible solution because it allows protecting them against the influences of the outside environment, increasing the heat-transfer area, and permitting the core material to withstand changes in volume of the PCM which take place as the phase change occurs, thus, allowing the development of small and portable thermal energy storage systems (Alkan et al. 2011).

Electrohydrodynamic processing is one technique increasingly being used for the microencapsulation of substances. This technique has proven to be a suitable method for encapsulation of several components, including biomedical compounds, functional food ingredients, PCMs and others substances within polymer matrices (Goldberg et al., 
2007; Lopez-Rubio et al., 2012; Pérez-Masiá et al., 2013). The electrohydrodynamic processing, commonly termed as electrospinning, is a technique whereby long nonwoven ultrafine structures, typically fibers with diameters of several tens to several hundreds of nanometers, may be formed by applying a high-voltage electric field to a solution containing polymers (Teo and Ramakrishna, 2006). As a result of the applied electric field, a polymer jet is ejected from the tip of a capillary through which a polymer solution is pumped, accelerated toward a grounded target and deposited thereon (Arecchi et al., 2010).

The aim of this work was to develop heat management materials of interest in food packaging for refrigeration applications by means of developing a electrospun coating incorporating a PCM which melts at $5^{\circ} \mathrm{C}$ (RT5), to be used onto polystyrene (PS) trays. The effects of storage temperature and ageing on the performance of the trays were also evaluated.

\section{MATERIALS AND METHODS}

\subsection{Materials}

Rubitherm RT5, a technical grade paraffin wax, was chosen as the PCM for refrigerated storage. It is based on a cut resulting from refinery production and it consists entirely of normal paraffin waxes (C14-C18). RT5 was purchased from Rubitherm Technologies GmbH (Berlin, Germany). Polystyrene trays were purchased from Poliestirenos Asturianos S.L (Asturias, Spain). Polystyrene (PS) commercial grade foam was supplied by Traxpo (Barcelona, Spain). N, N-dimethylformamide (DMF) with 99\% purity and trichloromethane (99 \%) were purchased from Panreac Quimica S.A. (Castellar del Vallés, Spain). All products were used as received without further purification. 
2.2.1 Preparation of heat management PS-trays.

PS trays were coated with PS/PCM mats produced by means of the high throughput electrohydrodynamic processing. The full process of the PCM encapsulation through a high voltage spinning methodology has been previously developed (patent application number: P201131063). The electrospun PS/PCM fibers were prepared according to Perez-Masia et al. (2013), by dissolving the required amount of PS, under magnetic stirring, in a solvent prepared with a mixture of trichloromethane:N,Ndimethylformamide $(70: 30 \mathrm{w} / \mathrm{w})$ in order to reach a $10 \%$ in weight $(\mathrm{wt} .-\%)$ of PS. PS/PCM fiber mats were directly electrospun onto a metal collector over 5 hours by means of a Fluidnatek® electrospinning pilot plant equipment from Bioinicia S.L. (Valencia, Spain) equipped with a variable high-voltage 0-60 kV power supply. PS/PCM solutions were electrospun under a steady flow-rate using a motorized high throughput multinozzle injector, scanning vertically towards a metallic grid used as collector. The distance between the needle and the collector was $28 \mathrm{~cm}$ and experiments were carried out at ambient temperature. The voltage of the collector and injector were set at $52 \mathrm{kV}$ and $44 \mathrm{kV}$, respectively.

The electrospun PS/PCM coatings presented a whitish appearance and, with the aim of obtaining a continuous pellicle, the PS/PCM coating $(\sim 50 \mathrm{~g})$ was deposited onto the PS trays and was annealed at $145^{\circ} \mathrm{C}$ for 1.5 min using a hot-plate hydraulic press (Carver, Inc., Wabash, USA) which also favoured the adhesion between materials.

\subsubsection{Samples conditioning and storage}


154 Samples were equilibrated in desiccators at $0 \% \mathrm{RH}$ by using silica gel and at two different temperatures 4 and $25^{\circ} \mathrm{C}$ for three months. PS-trays containing the PS/PCM coating were taken from the desiccators at different time intervals $(0,7,15,30,45,60$ and 90 days) and DSC and FTIR analysis were carried out.

\subsection{Characterization of PS trays with the ultrathin fiber-structured PS/PCM} coating.

\subsubsection{Scanning Electron Microscopy (SEM).}

SEM was conducted on a Hitachi microscope (Hitachi S-4100) at an accelerating voltage of $10 \mathrm{kV}$. Samples were cryo-fractured after immersion in liquid nitrogen and subsequently sputtered with a gold-palladium mixture under vacuum before their morphology was examined using SEM. The thickness of the coating layer was measured by means of the Adobe Photoshop CS3 extended software from the SEM micrographs in their original magnification.

\subsubsection{Differential Scanning Calorimetry (DSC)}

Thermal analyses of the samples were carried out on a DSC-7 calorimeter (Perkin Elmer Inc., Norwalk, USA) from -20 to $20^{\circ} \mathrm{C}$ under a nitrogen atmosphere using a refrigerating cooling accessory (Intracooler 2) (Perkin Elmer Inc., Norwalk, USA). The scanning rate was $2^{\circ} \mathrm{C} / \mathrm{min}$ in order to minimize the influence of this parameter in the thermal properties. The amount of material used for the DSC experiments was adjusted so as to have a theoretical PCM content of 1-2 mg approximately. The enthalpy results obtained were, thus, corrected according to this PCM content. All tests were carried out in triplicate. 
2.3.3. Attenuated Total Reflectance Infrared Spectroscopy (ATR-FTIR).

ATR-FTIR spectra of polystyrene (PS) polymer, PS tray, pure RT5 (PCM), PS/PCM fibers and PS tray structures were collected at $25^{\circ} \mathrm{C}$ in a FTIR Tensor 37 equipment (Bruker, Rheinstetten, Germany). The spectra were collected in the different materials by averaging 20 scans at $4 \mathrm{~cm}^{-1}$ resolution. The experiments were repeated twice to verify that the spectra were consistent between individual samples.

\subsubsection{Temperature profiles.}

The temperature profiles of the PS trays with and without the PS/PCM coating were compared. To this end, all samples were frozen at $-18^{\circ} \mathrm{C}$ for 1 day. Then, the surface temperature evolution was registered at room temperature $\left(20^{\circ} \mathrm{C}\right)$ by using an infrared thermometer MS Plus (PCE Instruments, Tobarra, Spain).

\subsubsection{Optical properties.}

Internal transmittance of the PS/PCM coating and PS-trays was determined through the surface reflectance spectra with a spectrocolorimeter CM-3600 (Minolta Co, Tokyo, Japan) with a $10 \mathrm{~mm}$ illuminated sample area. Measurements were taken from three replicates by using both a white and black background and Kubelka-Munk theory for multiple scattering was applied to the sample reflection spectra. Internal transmittance (Ti) was calculated from the reflectance of the sample layer backed by a known reflectance and the reflectance of the film on an ideal black background (Hutchings 1999). Moreover, CIE- $L^{*} a^{*} b^{*}$ coordinates (CIE, 1986) were obtained by the infinite reflection spectra of the samples, using D65 illuminant $/ 10^{\circ}$ observer in order to calculate the whiteness index (WI) of the samples (Eq. (1)). 


\subsection{Statistical Analysis.}

Statgraphics Plus for Windows 5.1 (Manugistics Corp., Rockville, USA) was used for carrying out statistical analyses of data through analysis of variance (ANOVA). Fisher's least significant difference (LSD) was used at the 95\% confidence level.

\section{RESULTS}

\subsection{Morphology and optical properties}

The main objective of this work was to develop PS trays containing PS/PCM coatings to maintain the chilling temperature of fresh food products along the cold-chain. The PS/PCM coating was previously observed by SEM (cf. Figure 1a). The surface images, showed a dense but opened structure with many beaded areas $(10.3 \pm 4.2 \mu \mathrm{m})$ within the fibrous $(1.6 \pm 0.6 \mu \mathrm{m})$ mat, and the cross-section images of the PS-trays (cf. Figure 1b) gave an idea of the coating's thickness $(\sim 78 \mu \mathrm{m})$ and compactness.

Optical properties of the PS trays containing, or not, the PS/PCM coating were evaluated and compared by means of the internal transmittance (Ti) where an increase in the internal distribution of transmittance is ascribed to an increase in transparency. Spectral distribution curves of internal transmittance are plotted in Figure 2. Lower Ti values $(\mathrm{Ti} \leq 15 \%)$ were obtained in all the samples as compared to those previously obtained for multilayer structures prepared with $\mathrm{PS}$ ( $\mathrm{Ti} \geq 50 \%$ ) which can be ascribed to the different nature of the PS used (Chalco-Sandoval et al. 2014). Considering these results, PS-trays and the corresponding PS-trays containing the ultrathin fiber-structured coating can be considered to have low transparency. The highest internal transmittance values were found for the PS tray whereas Ti values decreased with the addition of the electrospun PS/PCM coating. 
230 From the reflectance spectra of an infinite thickness sample, Lightness $\left(L^{*}\right)$, hue $\left(h_{\mathrm{ab}}^{*}\right)$,

231 Chroma $\left(C^{*}{ }_{\mathrm{ab}}\right)$ and Whiteness Index (WI) of each sample were obtained (Table 1). PS

coherent with their lower internal transparency. Both samples showed low Chroma values, corresponding with the white appearance of them. Whiteness is an attribute of colors of high luminous reflectance and low purity situated in a relatively small region of the color space. Thus, the white color attribute is distinguished by its high lightness $\left(L^{*}\right)$ and its very low (ideally zero) saturation $\left(C^{*}{ }_{\mathrm{ab}}\right)$.

\subsection{ATR-FTIR analysis of PS/PCM coating}

The presence of PCM onto the PS trays and within the PS/PCM fibers was qualitatively evaluated by ATR-FTIR spectroscopy. Figure 3 shows the ATR-FTIR spectra of the PS tray (with and without the PS/PCM coating) and the pure RT5 analyzed at $20^{\circ} \mathrm{C}$. At this temperature, the pure RT5 is characterized by the $-\mathrm{CH}_{2}$ and $-\mathrm{CH}_{3}$ stretching vibration bands at 2956, 2922 and $2854 \mathrm{~cm}^{-1}$ and these bands were also observed in the PS/PCM coatings even though they were overlapped with the spectral bands from the PS. From Figure 3 it can be clearly observed that the intensity of the characteristic bands of the PCM was greater in non-stored samples, indicating a greater amount of PCM within the structures, which was directly related with the enthalpy values commented on above, since higher crystallization and melting enthalpies implied greater encapsulation efficiency. In order to qualitatively evaluate PCM loading, the relative intensity of a PCM band with respect to a polymer spectral band was calculated in non-stored and stored structures and the results are compiled in Table 2. Specifically, the bands at 2956 $\mathrm{cm}^{-1}$ and $1493 \mathrm{~cm}^{-1}$ were selected for RT5 and PS, respectively. Similarly to that observed for PS-based multilayer structures (Chalco-Sandoval et al., 2014), the 
calculated spectral band ratio of the non-stored PS trays structures was greater than in stored ones and the relative intensity of the PCM bands decreased after 3 month of storage, mainly in those stored at $25^{\circ} \mathrm{C}$. The greater decrease in samples stored at $25^{\circ} \mathrm{C}$ was closely related to the partial diffusion out of the paraffin and thus, with the lower enthalpy values found in the stored samples.

\subsection{Thermal properties of the developed PS trays with the ultrathin fiber-} structured PS/PCM coating.

The thermal properties of the PS trays containing the electrospun PS/PCM coating were analyzed by DSC during three months of storage and this technique was also used to determine the RT5 encapsulation efficiency. Table 2 gathers the enthalpy values, melting and crystallization temperatures as well as the supercooling degree of the pure RT5 and the PS-trays containing the electrospun PS/PCM coating. The melting temperature of the PS trays with the coating was in the same range as the melting temperature of the pure RT5 $\left(\sim 7.2^{\circ} \mathrm{C}\right)$, indicating that similar PCM crystals were formed within the encapsulation structures. Nevertheless, while pure RT5 crystallizes at $5.3{ }^{\circ} \mathrm{C}$, a greater supercooling degree was observed for PS-trays containing the coating. This phenomenon can be ascribed to a reduction of the RT5 particle size, since the number of nuclei needed to initiate the crystallization process decreased with reducing the diameter of the RT5 drops inside the fibers. In fact, two crystallization temperatures were detected for the paraffin blend contained within the PS trays which can be ascribed to the multiple crystallization processes of the $\mathrm{N}$-alkanes ascribed to the rotator phase transitions which are observed in these paraffins when their particle size is reduced (Zhang et al. 2012; Delgado et al. 2012; Zhang et al. 2004). 
As deduced from Table 2, the thermal behavior of the PCM varied when it was encapsulated and upon ageing since PS trays containing the ultrathin fiber-structured PS/PCM coating showed lower melting and crystallization enthalpy values than those of the non-encapsulated PCM. This fact could be explained by lower encapsulation efficiencies than theoretically calculated and also by the PCM diffusion throughout the PS matrix along storage. Moreover, one should also consider the potential PCM-PS interactions which could hinder paraffin crystallization. Similar to the results previously reported for multilayer structures prepared with PS and PS/PCM fibers (ChalcoSandoval et al., 2014), the storage temperature was the determining factor in the reduction of melting and crystallization enthalpies of the samples with time, showing a decrease of $\sim 56-58 \%$ and $\sim 30-40 \%$ in samples stored at $25^{\circ} \mathrm{C}$ and $4^{\circ} \mathrm{C}$, respectively. This can be ascribed to the physical state of the PCM since the paraffin was in solid state (crystallized) at $4^{\circ} \mathrm{C}$ and, thus, better retained within the fibrous mat. However, the liquid state of the PCM at room temperature could facilitate its diffusion throughout the PS matrix favoring PCM-PS interactions which could also hinder paraffin crystallization with storage time. The loss of heat management capacity over the storage time was significantly greater than that previously reported for the PS/PCM and PCL/PCM slabs (Chalco-Sandoval et al., 2014) probably due to the greater thickness of the slabs, which thus better protected the PCM from the heat treatment applied.

\subsection{Evaluation of the RT5 Encapsulation Efficiency and Loading.}

The encapsulation efficiency was calculated by dividing the experimental melting enthalpy obtained for the hybrid materials by the experimental melting enthalpy obtained for pure RT5, considering the quantity of the PCM added to the electrospinning solutions. The encapsulation efficiency is closely related with the heat storage capacity of the PS trays. Figure 4 shows the encapsulation yield and the 
calculated total amount of the encapsulated PCM derived from the DSC results of the hybrid structures stored at 4 and $25^{\circ} \mathrm{C}$. PS fibers were able to encapsulate a heat storage capacity equivalent to $\sim 34$ wt. $\%$ of the PCM (core material) which corresponded to an encapsulation efficiency of ca. $78 \%$. The storage temperature played an important role in the reduction of the heat storage capacity, showing a decrease up to 56-58\% in PS trays stored at $25^{\circ} \mathrm{C}$ and $30-40 \%$ in samples stored at chilling temperature $\left(4^{\circ} \mathrm{C}\right)$. The decrease in the encapsulation efficiency and thus, in the heat storage capacity of the PS trays stored at $25^{\circ} \mathrm{C}$ could be ascribed to the heat treatment applied during the coating formation and also to the liquid state of the RT5 when stored at $25^{\circ} \mathrm{C}$.

\subsection{Heat storage capacity of PS trays with the ultrathin fiber-structured PS/PCM coating.}

The thermal buffering capacity of the encapsulated RT5 was measured by recording the temperature profiles of the PS trays with and without the PS/PCM coatings (Figure 5) stored at $-18^{\circ} \mathrm{C}$ and analyzed at room temperature $\left(20^{\circ} \mathrm{C}\right)$. From Figure 5, it is clearly observed that the presence of the coating containing the PCM, effectively extended the time needed to increase the temperature above the chilling temperature of food products when compared to the neat PS tray. The increase in time is related to the latent energy for melting the PCM, but also to the insulation effect of the PS/PCM coatings. The slope of the time-temperature curve of the PS trays containing PS/PCM trays decreased in the melting range of the PCM.

\section{CONCLUSIONS}

In this work, heat management materials consisting on PS trays coated with the electrospun PS/PCM layers have been developed. A temperature mismatch between 
melting and crystallization phenomena (the so-called supercooling effect) was observed in the PS-trays containing the electrospun PS/PCM layer, mainly ascribed to the reduced PCM drop size inside the fibers. Results showed that PS fibers were able to encapsulate a heat storage capacity equivalent to $\sim 34$ wt.\% of the PCM (core material) which corresponded to an encapsulation efficiency of ca. $78 \%$. The storage temperature was the determining factor in the reduction of heat management capacity over the storage time, showing a decrease of $\sim 56-58 \%$ in those stored at $25^{\circ} \mathrm{C}$ and $30-40 \%$ in samples stored at chilling temperature $\left(4^{\circ} \mathrm{C}\right)$. Although electrospinning seems to be a promising technology to develop heat management materials, further works need to be developed to improve the encapsulation efficiency and heat storage capacity of the developed polymeric materials over storage time.

Acknowledgments The authors acknowledge financial support from EU project of the FP7 FRISBEE for financial support. W. Chalco-Sandoval thanks to Ministry of Higher Education, Science, Technology and Innovation (SENESCYT) from Ecuador for the pre-doctoral grant. M. J. Fabra is recipient of a Juan de la Cierva contract from the Spanish Ministry of Economy and Competitivity, respectively.

\section{REFERENCES}

Alkan, C., Sarı, A., \& Karaipekli, A. (2011). Preparation, thermal properties and thermal reliability of microencapsulated n-eicosane as novel phase change material for thermal energy storage. Energy Conversion and Management, 52(1), 687-692.

Arecchi, A., Mannino, S., \& Weiss, J. (2010). Electrospinning of poly(vinyl alcohol) nanofibres loaded with hexadecane nanodroplets. J Food Sci, 75(6), N80-88. 
354 Chalco-Sandoval, W., Fabra, M. J., López-Rubio, A., \& Lagaron, J. M. (2014). 355 Electrospun heat management polymeric materials of interest in food refrigeration and 356 packaging. Journal of Applied Polymer Science, 131(16), n/a-n/a, 357 doi:10.1002/app.40661.

358 Delgado, M., Lázaro, A., Mazo, J., \& Zalba, B. (2012). Review on phase change 359 material emulsions and microencapsulated phase change material slurries: Materials, 360 heat transfer studies and applications. Renewable and Sustainable Energy Reviews, 361 16(1), 253-273.

Fang, G., Li, H., Yang, F., Liu, X., \& Wu, S. (2009). Preparation and characterization of nano-encapsulated n-tetradecane as phase change material for thermal energy storage. Chemical Engineering Journal, 153(1-3), 217-221.

Farid, M. M., Khudhair, A. M., Razack, S. A. K., \& Al-Hallaj, S. (2004). A review on phase change energy storage: materials and applications. Energy Conversion and Management, 45(9-10), 1597-1615.

Gin, B., \& Farid, M. M. (2010). The use of PCM panels to improve storage condition of frozen food. Journal of Food Engineering, 100(2), 372-376.

Goldberg, M., Langer, R., \& Jia, X. (2007). Nanostructured materials for applications in drug delivery and tissue engineering. Journal of Biomaterials Science, Polymer Edition, 18(3), 241-268.

Hutchings, J. B. (1999). Food and colour appearance (2nd ed.). 443 Gaithersburg, USA: 444 Chapman and Hall Food Science Book, Aspen Publication.

James, S. J., James, C., \& Evans, J. A. (2006). Modelling of food transportation systems - a review. International Journal of Refrigeration, 29(6), 947-957.

Jin, Y., Lee, W., Musina, Z., \& Ding, Y. (2010). A one-step method for producing microencapsulated phase change materials. Particuology, 8(6), 588-590. 
Laguerre, O., Ben Aissa, M. F., \& Flick, D. (2008). Methodology of temperature prediction in an insulated container equipped with Phase Change Materials. (Vol. 802, pp. 83-90).

Lopez-Rubio, A., Sanchez, E., Wilkanowicz, S., Sanz, Y., \& Lagaron, J.M. (2012). Electrospinning as a useful technique for the encapsulation of living bifidobacteria in food hydrocolloids. Food Hydrocolloids, 28, 159-167.

Oró, E., de Gracia, A., \& Cabeza, L. F. (2013). Active phase change material package for thermal protection of ice cream containers. International Journal of Refrigeration, 36(1), 102-109.

Oró, E., de Gracia, A., Castell, A., Farid, M. M., \& Cabeza, L. F. (2012). Review on phase change materials (PCMs) for cold thermal energy storage applications. Applied Energy, 99, 513-533.

Perez-Masia, R., Lopez-Rubio, A., Fabra, M. J., \& Lagaron, J. M. (2013). Biodegradable polyester-based heat management materials of interest in refrigeration and smart packaging coatings. Journal of Applied Polymer Science, 130(5), 3251-3262. Pérez-Masiá, R., López-Rubio, A., \& Lagarón, J. M. (2013). Development of zeinbased heat-management structures for smart food packaging. Food Hydrocolloids, 30(1), 182-191.

Sharma, A., Tyagi, V. V., Chen, C. R., \& Buddhi, D. (2009). Review on thermal energy storage with phase change materials and applications. Renewable and Sustainable Energy Reviews, 13(2), 318-345.

Teo, W. E., \& Ramakrishna, S. (2006). A review on electrospinning design and nanofibre assemblies. Nanotechnology, 17(14), R89-R106. 
402 Zhang, S., Wu, J.-Y., Tse, C.-T., \& Niu, J. (2012). Effective dispersion of multi-wall carbon nano-tubes in hexadecane through physiochemical modification and decrease of supercooling. Solar Energy Materials and Solar Cells, 96, 124-130.

405 Zhang, X.-X., Tao, X.-m., Yick, K.-1., \& Wang, X.-c. (2004). Structure and thermal 406 stability of microencapsulated phase-change materials. Colloid \& Polymer Science, $407 \quad 282(4), 330-336$.

408 Yannick, A., 2006. European Patent No FR 2930739.

409 
410 Table 1. Colour coordinates ( $\mathrm{L}^{*}, \mathrm{~h}^{*}$ and $\mathrm{C}^{*}$ ) and whiteness index (WI) of PS-trays 411 containing or not PS/PCM pad.

\begin{tabular}{|l|c|c|c|c|}
\hline Samples & $\mathbf{L}^{*}$ & $\mathbf{h}^{*}$ & $\mathbf{C}^{*}$ & WI \\
\hline PS-tray & $90.5(0.4)^{\mathrm{a}}$ & $102(0.9)^{\mathrm{a}}$ & $0.10(0.06)^{\mathrm{a}}$ & $90.5(1.1)^{\mathrm{a}}$ \\
\hline PS-tray with PS/PCM pad & $93.3(0.6)^{\mathrm{b}}$ & $98(1.0)^{\mathrm{b}}$ & $0.22(0.05)^{\mathrm{a}}$ & $93.3(0.5)^{\mathrm{b}}$ \\
& & & & \\
\hline
\end{tabular}


413 Table 2. Ratio of PS/PCM of non-stored and stored samples at 4 and $25^{\circ} \mathrm{C}$. Mean value (standard deviation).

\begin{tabular}{|c|c|c|c|}
\hline Material & Non-stored & Stored 3 months at $4{ }^{\circ} \mathrm{C}$ & Stored 3 months at $25^{\circ} \mathrm{C}$ \\
\hline PS-trays with the coating & $1.29(0.2)$ & $1.1(0.3)$ & $0.84(0.2)$ \\
\hline
\end{tabular}

414 
Table 3. Thermal properties of the Rubitherm 5 (RT5) and the PS trays structures.

Mean value (standard deviation).

\begin{tabular}{|c|c|c|c|c|c|c|c|c|c|c|c|c|}
\hline \multirow{2}{*}{$\begin{array}{l}\text { Time } \\
\text { (days) }\end{array}$} & \multicolumn{2}{|c|}{$\operatorname{Tm}\left({ }^{\circ} \mathrm{C}\right)$} & \multicolumn{2}{|c|}{$\begin{array}{c}\Delta \mathrm{Hm}(\mathrm{J} / \mathrm{g} \\
\text { PCM) }\end{array}$} & \multicolumn{2}{|c|}{$\mathrm{Tc}_{\mathbf{1}}\left({ }^{\circ} \mathrm{C}\right)$} & \multicolumn{2}{|c|}{$\mathrm{Tc}_{2}\left({ }^{\circ} \mathbf{C}\right)$} & \multicolumn{2}{|c|}{$\begin{array}{c}\Delta \mathrm{Hc}(\mathrm{J} / \mathrm{g} \\
\text { PCM) }\end{array}$} & \multicolumn{2}{|c|}{$\begin{array}{c}\text { Supercooling } \\
\left({ }^{\circ} \mathrm{C}\right)\end{array}$} \\
\hline & $4^{\circ} \mathrm{C}$ & $25^{\circ} \mathrm{C}$ & $4^{\circ} \mathrm{C}$ & $25^{\circ} \mathrm{C}$ & $4^{\circ} \mathrm{C}$ & $25^{\circ} \mathrm{C}$ & $4^{\circ} \mathrm{C}$ & $25^{\circ} \mathrm{C}$ & $4^{\circ} \mathrm{C}$ & $25^{\circ} \mathrm{C}$ & $4^{\circ} \mathrm{C}$ & $25^{\circ} \mathrm{C}$ \\
\hline $\begin{array}{l}\text { Pure } \\
\text { RT5 }\end{array}$ & \multicolumn{2}{|c|}{$7.2(0.1)$} & \multicolumn{2}{|c|}{$142(3)$} & \multicolumn{4}{|c|}{$5.3(0.2)$} & \multicolumn{2}{|c|}{$142(3)$} & \multicolumn{2}{|c|}{$1.9(0.2)$} \\
\hline 0 & $\begin{array}{c}7.2(0.1)^{\mathrm{a}} \\
1\end{array}$ & $\begin{array}{c}7.2(0.1)^{\mathrm{a}} \\
1\end{array}$ & $\begin{array}{c}107(1) \\
\text { al }\end{array}$ & $\begin{array}{c}107(1) \\
\text { a1 }\end{array}$ & $\begin{array}{c}5.7(0.2)^{\mathrm{a}} \\
1\end{array}$ & $\begin{array}{c}5.7(0.1)^{\mathrm{a}} \\
2\end{array}$ & $3.2(0.1)^{\mathrm{a} 1}$ & $\begin{array}{c}3.2(0.1)^{\mathrm{a}} \\
2\end{array}$ & $\begin{array}{c}\text { 109(1) } \\
\text { a1 }\end{array}$ & $\begin{array}{c}107(1) \\
\text { a1 }\end{array}$ & $\begin{array}{c}1.5(0.2) \\
\text { a1 }\end{array}$ & $\begin{array}{c}1.5(0.1) \\
\text { a1 }\end{array}$ \\
\hline 7 & $\begin{array}{c}7.3(0.1)^{\mathrm{a}} \\
1\end{array}$ & $\begin{array}{c}7.3(0.1)^{\mathrm{a}} \\
1\end{array}$ & $\begin{array}{c}104(1) \\
\text { b1 }\end{array}$ & $98(1)^{\mathrm{b} 2}$ & $\begin{array}{c}5.7(0.1)^{\mathrm{a}} \\
1\end{array}$ & $\begin{array}{c}5.7(0.1)^{\mathrm{a}} \\
2\end{array}$ & $\begin{array}{c}3.3(0.1)^{\mathrm{ab}} \\
1\end{array}$ & $\begin{array}{c}3.3(0.1)^{\mathrm{a}} \\
\text { b2 }\end{array}$ & $\begin{array}{c}103(1) \\
\text { b1 }\end{array}$ & $98(1)^{\mathrm{b} 2}$ & $\begin{array}{c}1.6(0.1) \\
\text { a1 }\end{array}$ & $\begin{array}{c}1.6(0.1) \\
\text { a1 }\end{array}$ \\
\hline 15 & $\begin{array}{c}7.4(0.1)^{\mathrm{a}} \\
\text { b1 }\end{array}$ & $\begin{array}{c}7.4(0.1)^{\mathrm{a}} \\
\text { b1 }\end{array}$ & $95(1)^{\mathrm{cl}}$ & $87(1)^{\mathrm{c} 2}$ & $\begin{array}{c}5.8(0.1)^{\mathrm{a}} \\
\mathrm{b} 1\end{array}$ & $\begin{array}{c}5.8(0.2)^{\mathrm{a}} \\
\mathrm{b} 1\end{array}$ & $\begin{array}{c}3.4(0.1)^{\mathrm{bc}} \\
1\end{array}$ & $\begin{array}{c}3.4(0.1)^{\mathrm{b}} \\
2\end{array}$ & $93(3)^{\mathrm{c} 1}$ & $87(1)^{\mathrm{c} 2}$ & $\begin{array}{c}1.6(0.1) \\
\text { a1 }\end{array}$ & $\begin{array}{c}1.6(0.3) \\
\text { al }\end{array}$ \\
\hline 30 & $\begin{array}{c}7.5(0.2)^{b} \\
1\end{array}$ & $\begin{array}{c}7.7(0.1)^{\mathrm{c}} \\
1\end{array}$ & $92(3)^{\mathrm{cl}}$ & $70(1)^{\mathrm{d} 2}$ & $\begin{array}{c}5.9(0.1)^{\mathrm{b}} \\
1\end{array}$ & $\begin{array}{c}6.1(0.1)^{\mathrm{c}} \\
1\end{array}$ & $\begin{array}{c}3.5(0.2)^{\mathrm{bc}} \\
\mathrm{d} 1\end{array}$ & $\begin{array}{c}3.6(0.1)^{\mathrm{c}} \\
2\end{array}$ & $92(5)^{\mathrm{c} 1}$ & $70(1)^{\mathrm{d} 2}$ & $\begin{array}{c}1.6(0.1) \\
\text { a1 }\end{array}$ & $\begin{array}{c}1.6(0.3) \\
\text { a1 }\end{array}$ \\
\hline 45 & $\begin{array}{c}7.7(0.2)^{b} \\
\mathrm{cl}\end{array}$ & $\begin{array}{c}7.8(0.1)^{\mathrm{c}} \\
1\end{array}$ & $85(1)^{\mathrm{d} 1}$ & $55(2)^{\mathrm{e} 2}$ & $\begin{array}{c}6.1(0.1)^{\mathrm{c}} \\
1\end{array}$ & $\begin{array}{c}6.2(0.1)^{\mathrm{c}} \\
2\end{array}$ & $\begin{array}{c}3.6(0.1)^{\mathrm{cd}} \\
\text { el }\end{array}$ & $\begin{array}{c}3.9(0.1)^{\mathrm{d}} \\
2\end{array}$ & $82(2)^{\mathrm{d} 1}$ & $55(2)^{\mathrm{el}}$ & $\begin{array}{c}1.6(0.1) \\
\text { a1 }\end{array}$ & $\begin{array}{c}1.6(0.1) \\
\text { a1 }\end{array}$ \\
\hline 60 & $\begin{array}{c}7.7(0.2)^{\mathrm{b}} \\
\mathrm{cl}\end{array}$ & $\begin{array}{c}8.0(0.1)^{\mathrm{c}} \\
\mathrm{d} 1\end{array}$ & $80(1)^{\mathrm{el}}$ & $49(3)^{\mathrm{e} 2}$ & $\begin{array}{c}6.2(0.1)^{\mathrm{c}} \\
\mathrm{d} 1\end{array}$ & $\begin{array}{c}6.4(0.2)^{\mathrm{c}} \\
\mathrm{d} 2\end{array}$ & $\begin{array}{c}3.7(0.2)^{\mathrm{de}} \\
1\end{array}$ & $\begin{array}{c}3.9(0.1)^{\mathrm{d}} \\
2\end{array}$ & $80(1)^{\mathrm{d} 1}$ & $49(1)^{\mathrm{f} 2}$ & $\begin{array}{c}1.6(0.1) \\
\text { a1 }\end{array}$ & $\begin{array}{c}1.6(0.2) \\
\text { a1 }\end{array}$ \\
\hline 75 & $\begin{array}{c}8.0(0.1)^{\mathrm{c}} \\
1\end{array}$ & $\begin{array}{c}8.3(0.1)^{\mathrm{d}} \\
1\end{array}$ & $79(1)^{\mathrm{el}}$ & $47(4)^{\mathrm{f} 2}$ & $\begin{array}{c}6.3(0.1)^{\mathrm{d}} \\
1\end{array}$ & $\begin{array}{c}6.6(0.1)^{\mathrm{d}} \\
1\end{array}$ & $\begin{array}{c}3.9(0.2)^{\mathrm{ef}} \\
1\end{array}$ & $\begin{array}{c}4.1(0.2)^{\mathrm{d}} \\
\text { e2 }\end{array}$ & $79(1)^{\mathrm{d} 1}$ & $\begin{array}{c}47(4)^{\mathrm{fg}} \\
2\end{array}$ & $\begin{array}{c}1.7(0.1) \\
\text { a1 }\end{array}$ & $\begin{array}{c}1.7(0.1) \\
\text { al }\end{array}$ \\
\hline 90 & $\begin{array}{c}8.1(0.1)^{\mathrm{d}} \\
1\end{array}$ & $\begin{array}{c}8.5(0.1)^{\mathrm{e}} \\
2\end{array}$ & $75(2)^{f 1}$ & $44(2)^{\mathrm{f} 2}$ & $\begin{array}{c}6.5(0.2)^{\mathrm{d}} \\
\text { e1 }\end{array}$ & $\begin{array}{c}6.8(0.1)^{\mathrm{e}} \\
1\end{array}$ & $4.1(0.1)^{\mathrm{fl}}$ & $\begin{array}{c}4.4(0.1)^{\mathrm{e}} \\
2\end{array}$ & $73(3)^{\mathrm{e} 1}$ & $44(2)^{g 2}$ & $\begin{array}{c}1.6(0.1) \\
\text { a1 }\end{array}$ & $\begin{array}{c}1.7(0.1) \\
\text { al }\end{array}$ \\
\hline
\end{tabular}

417 


\section{Figure captions}

428 Figure 1. Surface (a) and cross-section (b) SEM images of the PS tray with the ultrathin 429 fiber-structured PS/PCM coating. Scale markers correspond to 20 and $200 \mu \mathrm{m}$ for the 430 surface and cross-section, respectively.

431 Figure 2. Spectral distribution of internal transmittance (Ti) of PS trays with and 432 without the ultrathin fiber-structured PS/PCM coating.

433 Figure 3. ATR-FTIR spectra of the neat PS polymer, PS tray, pure RT5 and non434 stored/stored PS tray with the PS/PCM coating measured at 4 and $25^{\circ} \mathrm{C}$. (A) Non-stored 435 PS tray containing the PS/PCM coating; (B) and (C) PS tray containing the PS/PCM 436 coating stored for 3 months at 4 and $25^{\circ} \mathrm{C}$, respectively.

437 Figure 4. Encapsulation efficiency and the calculated amount of the RT5 (\%) 438 encapsulated in the PS-tray systems. (a) Efficiency (\%) at $4{ }^{\circ} \mathrm{C}$ and $25^{\circ} \mathrm{C}$; (b) $\%$ RT5 at $439 \quad 4^{\circ} \mathrm{C}$ and $25^{\circ} \mathrm{C}$.

440 Figure 5. Surface temperature as a function of time for PS tray with and without the 441 ultrathin fiber-structured PS/PCM coating. 
Click here to download high resolution image

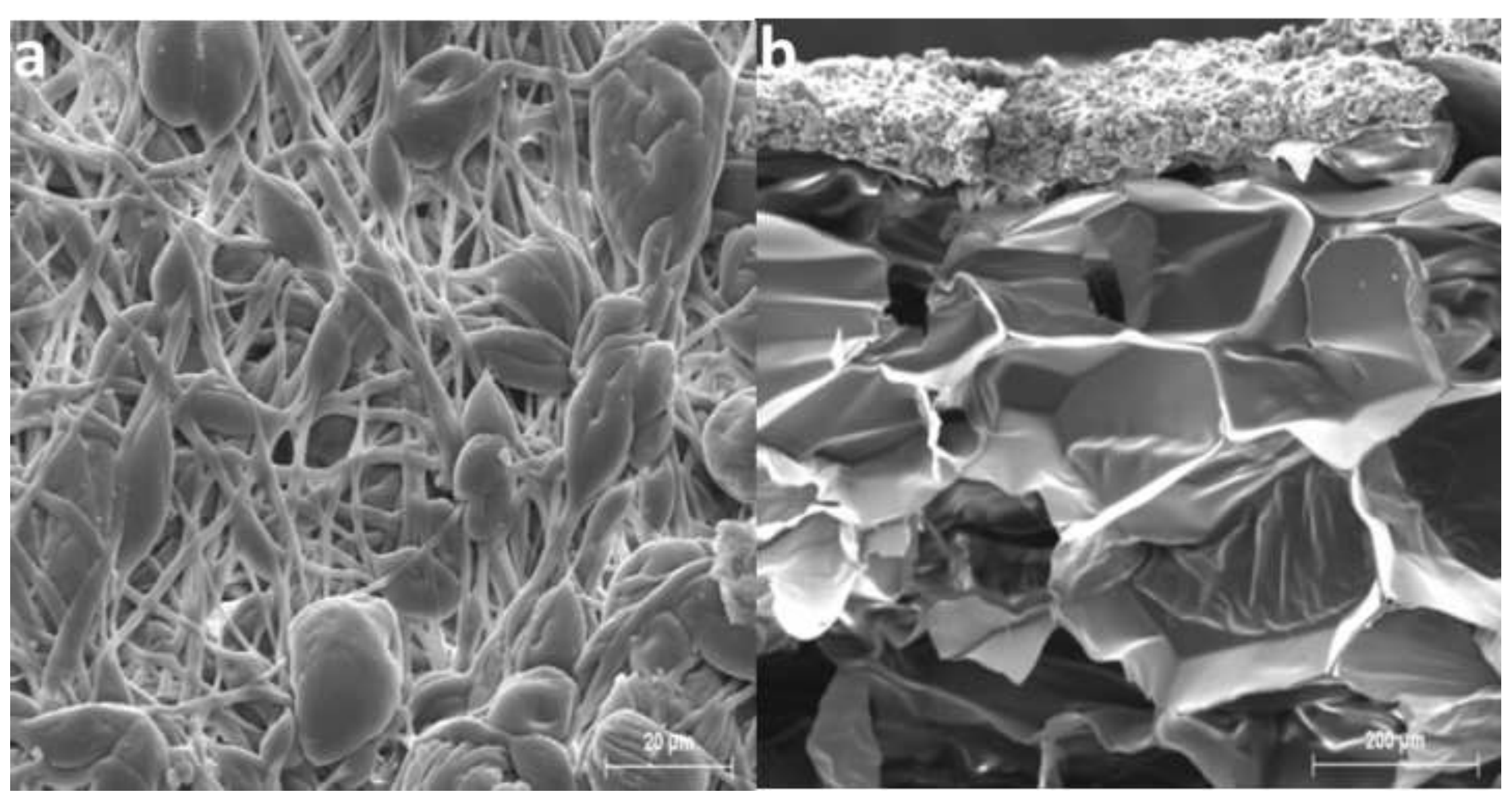


Click here to download high resolution image

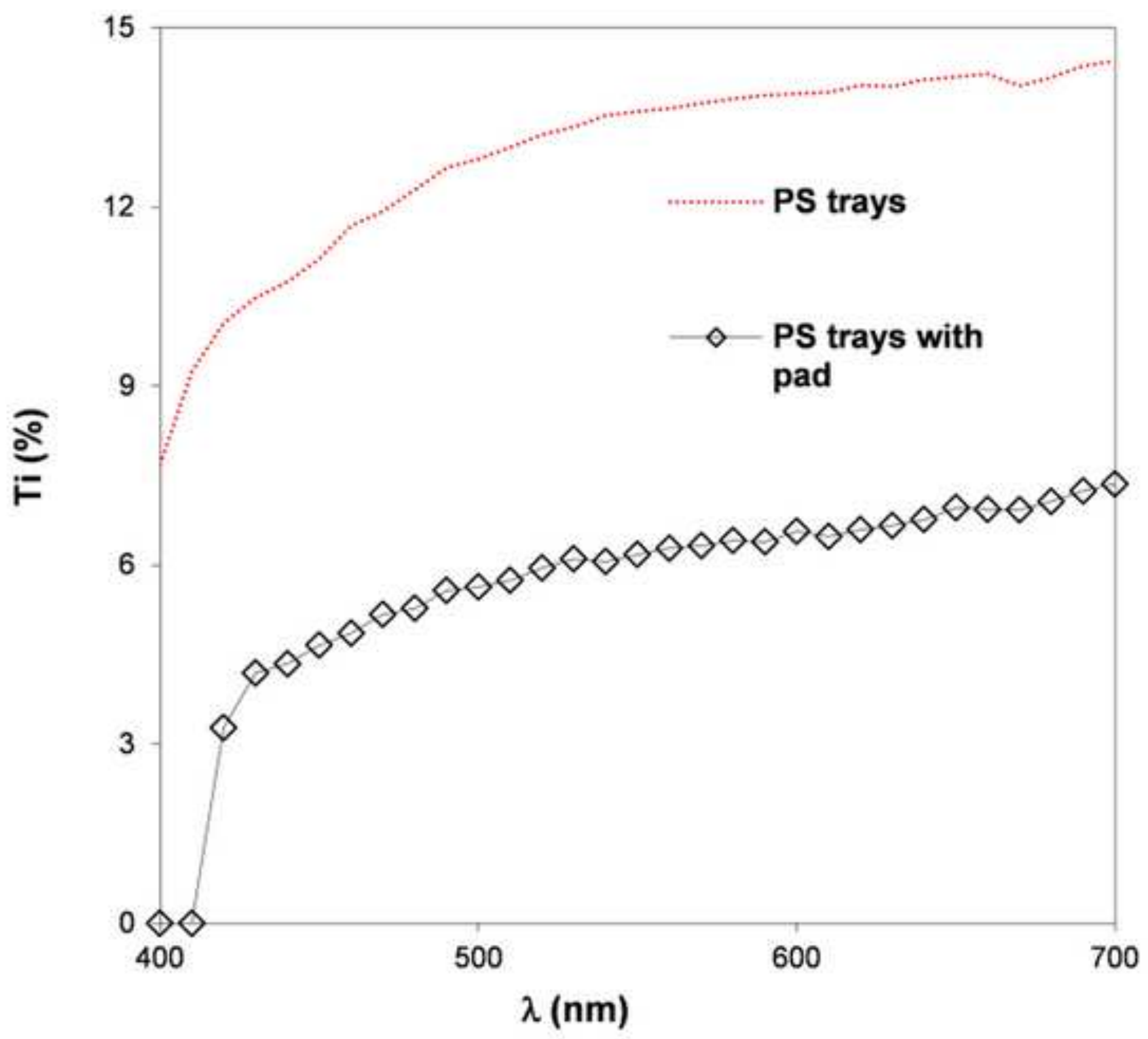




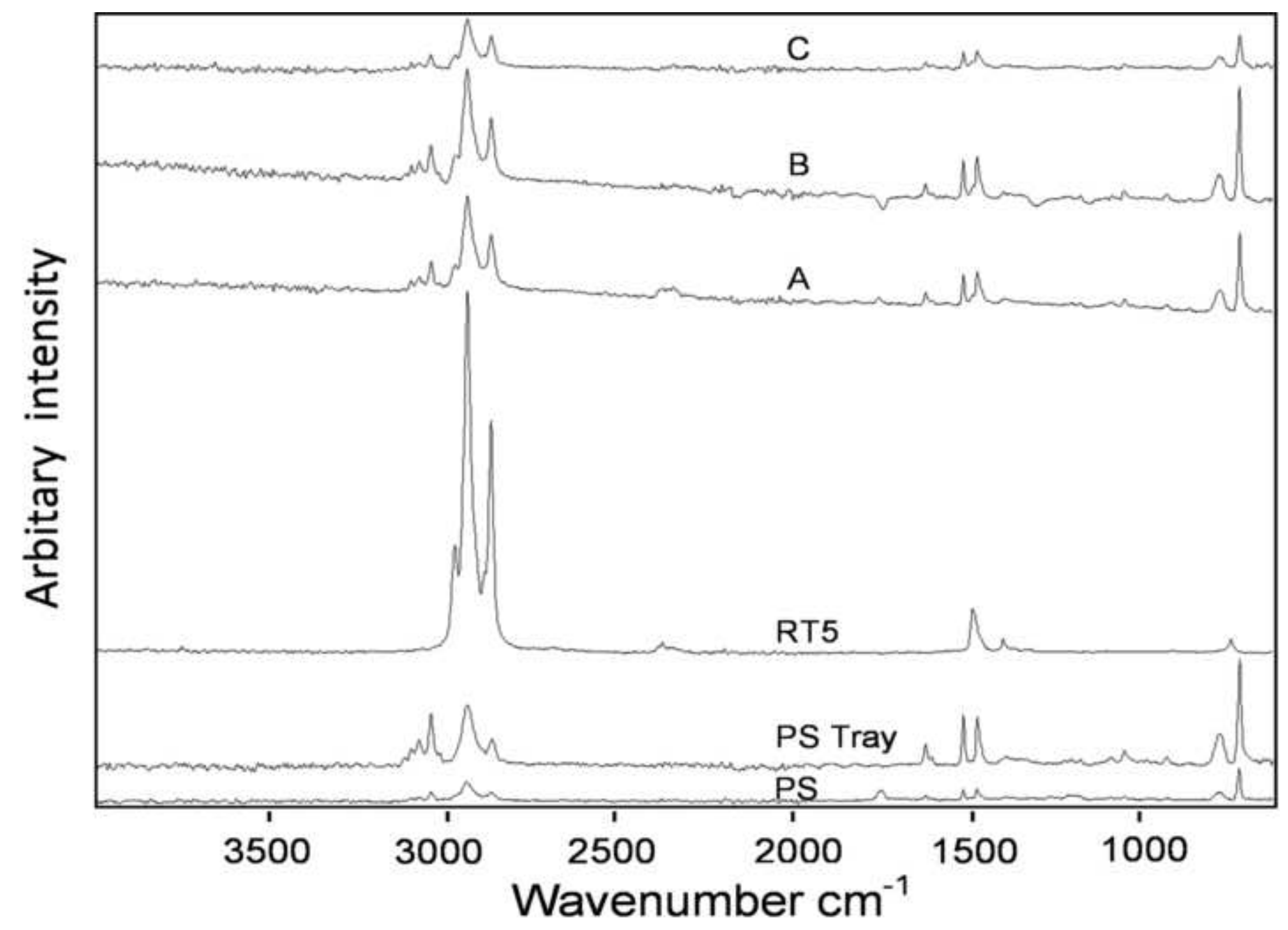


Click here to download high resolution image

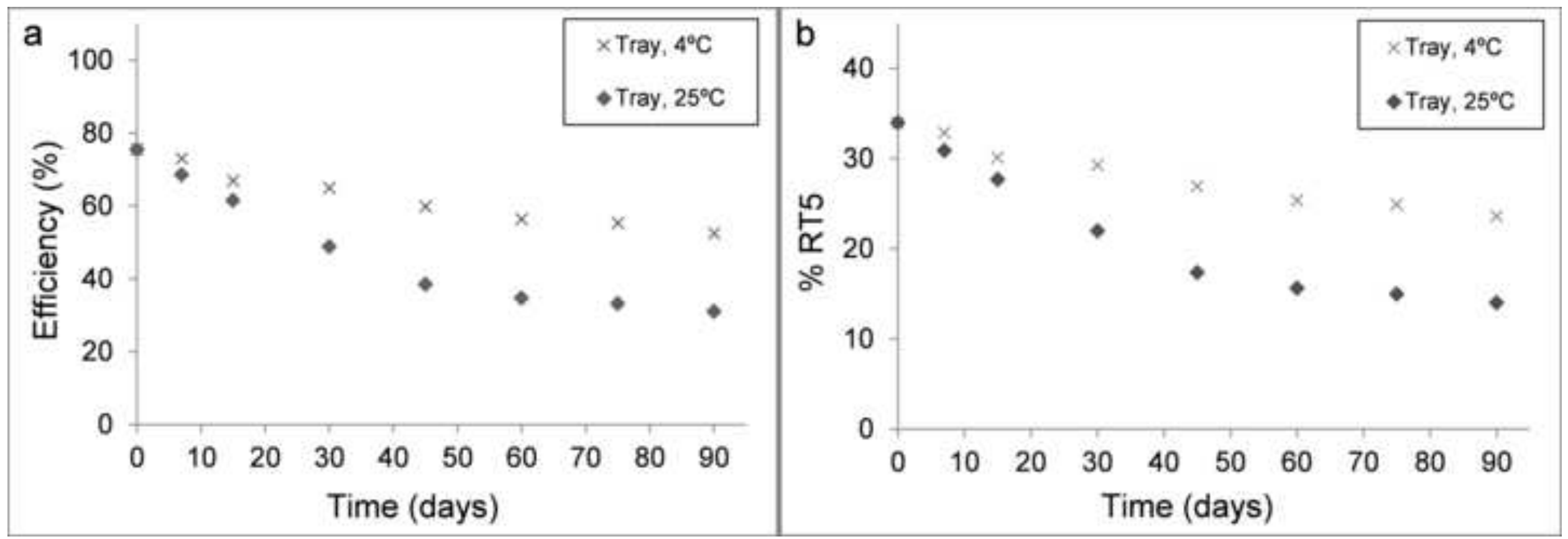




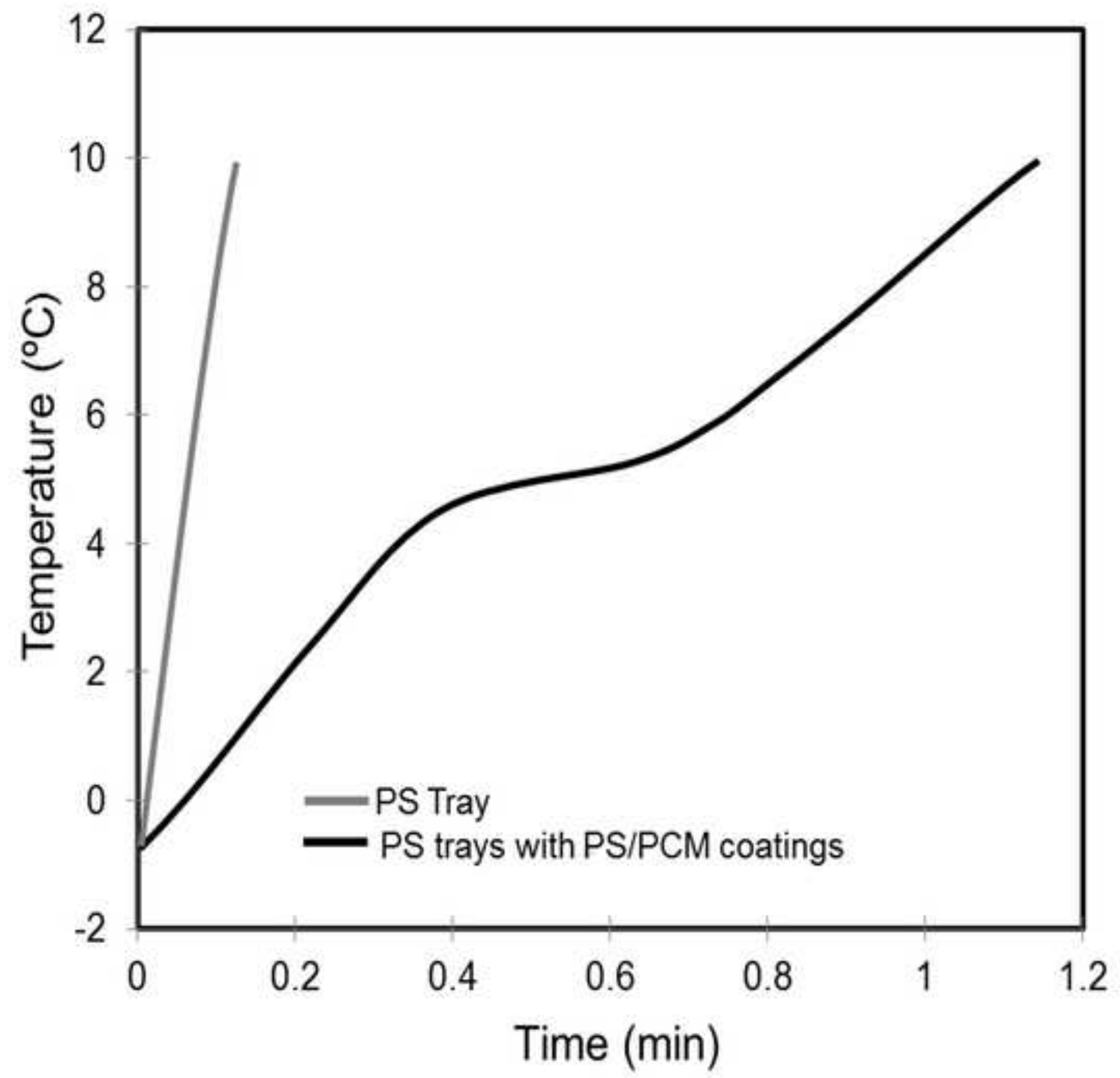

